Surg Clin North Am. 2011 December ; 91(6): 1149-vii. doi:10.1016/j.suc.2011.08.009.

\title{
Physiology of Weight Loss Surgery
}

\author{
Chan W. Park, MD and Alfonso Torquati, MD, MSCI ${ }^{\star}$ \\ Duke Endosurgery, Department of Surgery, Duke University, DUMC 3351, Duke University \\ Medical Center, Durham, NC 27713, USA
}

\section{Keywords}

Bariatric surgery; Diabetes; Gastric bypass; Incretins; Adipokines; Cytokines

\section{WHY (ARE PEOPLE SO FAT?)}

Several hypotheses and theories have been introduced to explain the origins of the current obesity epidemic. In 1962, a geneticist by the name of James V. Neel ${ }^{1}$ presented his theory of how the progress of natural human evolution favored the perpetuation of obesity and diabetes promoting "thrifty genes." ${ }^{1}$ He proposed that those individuals who had thrifty genes were better able to extract nutrients from ingested food and were more efficient in accumulating fat during times of abundance, and this resulted in an evolutionary advantage for these individuals during times of famine or food scarcity. Over time, survival of individuals with thrifty genes was favored compared with those with other genes. In light of the abundance of food in today's society and changes toward more sedentary lifestyles, this theory provides a plausible explanation for the obesity epidemic.

Opponents of this theory point to the archaeological records that refute the idea that famines were a commonly occurring phenomenon and that these events had a devastating impact on human survival. ${ }^{2}$ Others are quick to point out that the basic principles of genetics dictate that, if thrifty genes received such favoritism throughout the course of human evolution, every person should be obese by now. ${ }^{2,3}$ Although 70 to 100 million Americans are obese today, this number still only represents a minority ( one-third) of the population; this seems to contradict the thrifty gene theory. 3,4

A more recent theory proposed by John Speakman ${ }^{3}$ incorporates the observation that not all modern humans are obese, and he proposes that the obese phenotype is the result of genetic drift; it is caused by a set of "drifty genes." ${ }^{3}$ With the elimination of predatory checks limiting the upper limit of human body weight, and perhaps accelerated by the increasing availability of food resources, humans are now in an evolutionary environment that fosters the perpetuation of fatter phenotypes. A common introduction, which most morbidly obese patients receive at their first bariatric surgery seminar, is that obesity is a result of too many calories consumed and not enough calories expended (eg, while running away from a predator).

The debate between thrifty and drifty genes continues, and the final verdict remains undelivered. It is plausible that the origins of obesity can be explained by these eloquent theories, but it is more likely that a combination of evolutionary events, socioeconomic factors, and biologic stressors have resulted in the current obesity epidemic. Regardless of

(c) 2011 Elsevier Inc. All rights reserved.

*Corresponding author. alfonso.torquati@duke.edu. 
which evolutionary theory is correct, obesity cannot be over-come without significant changes involving both caloric intake and energy expenditure. At some point in an obese person's life, the balance between caloric intake and energy expenditure is lost, and only by reestablishing a negative balance can weight loss and resolution of obesity occur. Bariatric surgery provides this counterbalance and allows the patient to realistically achieve weight loss goals and minimize the detrimental effects of comorbid diseases.

The clinical outcomes achieved by bariatric surgery have been impressive. ${ }^{5-8}$ However, the physiologic mechanisms and complex metabolic effects of bariatric surgery are only beginning to be understood. Ongoing research has contributed a large amount of data on the science behind obesity and its treatment, and this article reviews the current understanding of metabolic and bariatric surgery physiology.

\section{HOW (DOES IT ALL WORK?)}

One of the earliest studies reporting on the effectiveness of surgery in treating obesityrelated diseases (ie, diabetes) was first published in 1955. In this study, Friedman and colleagues ${ }^{9}$ reported observing "the amelioration of diabetes mellitus following subtotal gastrectomy." Several decades later, Pories and colleagues ${ }^{10}$ reviewed their experience with gastric bypass surgery performed on obese patients and showed effective and durable weight loss (in a 14-year period) along with an $83 \%$ resolution of diabetes (defined as normoglycemia without medications). Further evidence for the effectiveness, long-term durability, and safety of bariatric surgery has continued to grow in the literature. ${ }^{5-8,10}$

Initially, the prevailing theory behind bariatric surgery was that there were 2 primary mechanisms for surgically induced weight loss: caloric restriction and/or nutrient malabsorption. Thus, bariatric operations have historically been categorized as restrictive and/or malabsorptive procedures. Restrictive procedures such as adjustable gastric banding (AGB), gastric plication, and (for the most part) sleeve gastrectomy all produce restriction of gastric capacity and limit the amount of oral intake possible in obese patients. In contrast, pure malabsorptive procedures such as jejunoileal bypass involve the surgical manipulation of the gastrointestinal tract, resulting in an alteration of the flow of nutrients and digestive enzymes through the gut. This operation results in significant malabsorption of nutrients, but has become less popular because of the unacceptably high long-term complication profile (profound malabsorption causes malnutrition, severe diarrhea, and even mortality). The benefits of both gastric restriction and intestinal malabsorption are combined in duodenal switch (DS) and Roux-en-Y gastric bypass (RYGB) procedures. Although producing the most impressive weight loss and comorbid disease resolution, the DS procedure is a more complex operation with both a higher level of difficulty and greater potential complication risk. Thus, RYGB is currently considered the gold standard bariatric surgical procedure given its favorable risk-benefit profile, and is the most commonly performed bariatric surgery today in the United States. ${ }^{7,8}$

Although these simple concepts of restriction and malabsorption provide a frame-work for categorizing bariatric operations, they do not fully explain the complex physiology of obesity and, furthermore, they grossly overlook the profound metabolic effects of bariatric surgery. In 2007, nearly 25 years after its development, the American Society for Bariatric Surgery changed its name to the American Society for Metabolic and Bariatric Surgery, reflecting a growing acceptance that bariatric surgery did more than just help patients lose weight. This acceptance was based on mounting evidence that obesity-related disease conditions often improved before any significant weight loss had taken place. Ongoing research continues to expand knowledge of bariatric surgery and its metabolic effects; as investigators continue their efforts, discovering deeper and increasingly complex 
interactions within the biochemical and hormonal network of human physiology, how bariatric surgery works is just beginning to be understood.

\section{The Enteroencephalic Endocrine Axis, Obesity, and Bariatric Surgery}

Since the time of Pavlov, the brain-body connection has been recognized in appetite stimulation and the physiology of eating. The process of nutrient ingestion begins even before food is consumed, and this is shown by anticipatory physiologic changes observed during the cephalic phase of ingestion, such as the release of various enteric hormones. ${ }^{11}$ During the meal, constant interplay continues between the visceral organs and the central regulatory centers of the brain, and the simple activity of eating has been shown to activate complex neural networks and stimulate reward centers of the brain. A recent study by Ochner and colleagues ${ }^{12}$ even showed that bariatric surgery can alter the patterns of neural activation in the mesolimbic reward centers in response to food. These changes were associated with a reduction in subjective appetite, and this highlights the importance of deciphering how bariatric surgery alters the communication pathways of the enteroencephalic endocrine axis. This axis is believed to be at the core of the physiologic regulation of human appetite, the process of nutrient intake, energy homeostasis, and human metabolism. A group of hormonal peptides facilitate the functions of this axis, and the following is a review of the key components of the enteroencephalic axis.

Ghrelin-One of the first hormones of interest for obesity and bariatric surgery is ghrelin. Also known as the hunger hormone, ghrelin is primarily produced by P/D1 cells located in the fundus of the stomach. ${ }^{13}$ Ghrelin levels increase significantly before a meal or when a person is believed to be hungry (hence its common name), and levels quickly diminish following a meal. Although it has many physiologic effects, ghrelin's key role in obesity and bariatric surgery is in the peptide's neurotrophic effects through the enteroencephalic endocrine axis. With receptors in the arcuate nucleus and the lateral hypothalamus, ghrelin stimulates the hypothalamic release of various neuropeptides such as neuropeptide Y (NPY) and growth hormone. The result is that ghrelin facilitates an orexigenic state, or a state of heightened appetite, via activation of the appetite-regulating and metabolism-regulating NPY neurons. Conversely, a significant reduction in the level of ghrelin, such as that observed immediately following a meal, results in a person achieving a sense of satiety. Ghrelin is the only known circulating orexin, a hormone that stimulates appetite.

Numerous studies have established the role of ghrelin as a premeal, appetite-stimulating hormone, and it is thought that ghrelin provides an important survival mechanism that stimulates nutrient intake in underweight people. ${ }^{14-18}$ However, the effects of ghrelin on human metabolism (and vice versa) may be more complicated than that. It has been shown that basal ghrelin levels may have an inverse relationship to body weight and energy balance. ${ }^{19,20}$ Basal ghrelin levels in individuals of normal and lower weight are significantly higher compared with the obese, and this may seem counterintuitive. Why would an obese person have lower levels of a hormone that causes appetite stimulation and favors greater caloric intake? In obese individuals, ghrelin's function as an orexin may be overshadowed by the existing, positive energy balance (more calories in/available than out). ${ }^{20}$ In a study by English and colleagues, ${ }^{21}$ obese subjects had significantly lower levels of basal ghrelin, but eating did not cause a significant decrease in the level of circulating ghrelin.21,22 Thus, in obese individuals, it seems that the protective function of ghrelin (against weight loss) has been turned off. In addition, the loss of a significant ghrelin level reduction following a meal may make it impossible for obese individuals to attain a sense of satiety after eating. How and why this occurs is not yet known, and further research may elucidate this physiologic phenomenon. 
Basal ghrelin levels increase as body weight is lost. In studies of normal-weight and obese subjects who lost weight through nonsurgical methods (diet and exercise), ghrelin levels were shown to increase when weight was lost. ${ }^{23-25}$ In another study, subjects who greatly restricted their own eating (ie, dieting) were found to have higher serum ghrelin levels compared with those who had less restrictive diets. ${ }^{26}$ What is most remarkable about this finding is that ghrelin levels were increased without any real change in weight. This reflex physiologic increase in ghrelin may make it increasingly difficult for people to lose weight through diet and exercise alone. In this sense, bariatric surgery may offer what no other therapy can. Studies in patients after RYGB have reported that plasma ghrelin is low despite significant weight loss. ${ }^{23,27}$ However, this finding has been inconsistent in the literature, with some studies reporting either no change or increased levels of ghrelin after bariatric surgery. ${ }^{28-31}$

The confusing picture of how bariatric surgery affects ghrelin may be caused by several factors, including differences in surgical technique, different ways to assay levels, as well as the complex and multiple physiologic functions of ghrelin..$^{32}$ The AGB procedure does not actively exclude ghrelin-producing cells within the stomach fundus, and this may account for the observations that ghrelin levels are higher after surgery. ${ }^{33,34}$ Likewise, sleeve gastrectomy and RYGB procedures involve exclusion of most of the ghrelin-producing stomach from the flow of nutrients, and favors a lower postsurgical ghrelin level. However, the extent of fundal exclusion may vary across the surgical centers performing these operations and this may contribute to the conflicting results. Recent scientific discoveries have identified multiple products of the gene that produces ghrelin (such as obestatin and desacyl ghrelin). These peptides have been shown to both augment and contradict the effects of ghrelin at differing receptor sites throughout the body. ${ }^{32}$ How these interactions affect the enteroendocrine functions of ghrelin are yet to be fully understood. In addition, a study by le Roux and colleagues ${ }^{35}$ reported that ghrelin did not affect appetite or stimulate food intake in patients who received a surgical vagotomy. Thus, bariatric operations involving gastric resection (and concomitant vagotomy) may effectively inhibit the role of ghrelin on appetite stimulation and food consumption.

Neuropeptide Y-At the level of the hypothalamus and the central regulatory centers of the brain, NPY is the dominant hormonal signal regulating nutrient intake and metabolism. NPY activity is ubiquitous throughout the body, and NPY is one of the most abundant neuropeptides in the human brain. NPY serves as the primary neuropeptide affecting numerous physiologic processes such as the regulation of circadian rhythm, stress response, and human metabolism. The complex and numerous physiologic relationships affecting NPY's role in the regulation of human metabolism and obesity are just beginning to be understood.

Release of NPY is stimulated by orexigenic signals such as ghrelin and inhibited by anorexigenic signals such as leptin and peptide YY (PYY). ${ }^{36}$ Among its many activities, NPY is a potent appetite-stimulating neuropeptide, and animal studies have confirmed the relationship between NPY and increased food intake as well as the development of obesity. ${ }^{37,38}$ In human studies, NPY has also been shown to promote obesity and the development of metabolic syndrome. ${ }^{39}$ This study showed that NPY promotes abdominal obesity and fat angiogenesis as a result of stress through an increased glucocorticoid (stress hormone) response. However, attempts to antagonize the orexigenic effects of NPY using novel NPY receptor antagonists have only been marginally effective..$^{40}$ In this large, multicenter, randomized controlled-study, NPY antagonism resulted in statistically significant, but clinically insignificant, weight loss ( $-2 \mathrm{~kg}$ more than control) in a 52-week period. Similarly, NPY levels following RYGB have been unimpressive. ${ }^{41}$ In this study, measurements of post-RYGB enteroendocrine changes in both diabetic and nondiabetic 
patients showed no significant changes in NPY despite effective weight loss and changes in body mass index (BMI) across groups. Thus, despite its known orexigenic effects, NPY as a potential target for obesity treatment is not well established.

Peptide YY-Another enterokine that acts on NPY neurons to regulate metabolism and appetite is PYY. Similar in structure and belonging to the same class of hormones as NPY, PYY is secreted in response to the presence of nutrients within the lumen of the gut by Lcells found throughout the small and large intestines (the highest concentrations of L-cells are found in the terminal ileum and colon.). ${ }^{36,42}$ In contrast with NPY, PYY exerts an anorexigenic stimulus on NPY neurons resulting in the termination of feeding and nutrient intake. In addition, PYY has many visceral effects such as the inhibition of gastrointestinal motility and reduction in both pancreatic and intestinal secretions. All of these effects promote a slowing of nutrient flow through the gastrointestinal tract, an effect referred to as the ileal brake, and PYY is considered to be one of the key components of this negativefeedback mechanism. ${ }^{43-45}$ The ileal brake negative-feedback mechanism is thought to be responsible for the suppression of appetite, leading to the termination of a meal.

Studies have confirmed PYY's effectiveness in suppressing appetite and nutrient consumption. ${ }^{46-48}$ In one study, PYY infusion was shown to reduce nutrient intake in both obese and lean subjects who received exogenous PYY. ${ }^{47}$ Another study quantified the effects of PYY administration and showed a 30\% decrease in the amount of food consumed during a buffet meal by both obese and lean subjects. In addition, this study also showed that PYY infusion caused a decrease in ghrelin levels, suggesting an interaction between appetite suppression and stimulation along the enteroendo-crine axis. ${ }^{48}$ Obese individuals have been shown to produce lower baseline levels of PYY compared with those who are lean and of normal weight, but not all reports have confirmed this finding. ${ }^{46-48}$

Bariatric surgery, RYGB in particular, has been shown to increase PYY levels, ${ }^{49}$ and this observation has been made as early as 48 hours after surgery. ${ }^{49-51}$ RYGB increases the rate of transit of nutrients to PYY-secreting areas of the intestine (ileum and colon), and this may cause the observed increase in postprandial PYY response after RYGB. Consistent with this mechanism, AGB did not increase PYY levels in obese patients, ${ }^{50}$ whereas RYGB and sleeve gastrectomy resulted in sustained increase of PYY levels during a 12-month study period. ${ }^{51}$ Furthermore, in meal-stimulation studies, increased postprandial PYY levels were seen in patients with RYGB, but not in patients undergoing medical weight loss. ${ }^{24}$

Leptin-Released primarily by adipose tissues, leptin acts at the level of the hypothalamus to counteract the orexigenic signals induced by ghrelin and NPY. Leptin activates propiomelanocortin containing (POMC) neurons which in turn release anorexigenic peptides such as a-melanocyte-stimulating hormone (a-MSH), and it also directly inhibits the release of NPY. ${ }^{52}$ Leptin is not an enteric hormone per se and is more appropriately categorized as an adipokine. Nevertheless, leptin's counter-activity to ghrelin and NPY makes it a key negative peptide signal within the enteroencephalic axis. Leptin promotes anorexic behavior and is believed to be intricately involved in the production of the sense of fullness or satiety following a meal.

In contrast with ghrelin, serum leptin levels are not dependent on short-term caloric intake; leptin levels are more reflective of an individual's metabolic profile over time and are dictated by the amount of existing adipose tissue. ${ }^{46}$ Thus, obese individuals have higher levels of circulating leptin; a counterintuitive phenomenon in light of leptin's known anorexigenic properties. However, it is thought that obese individuals become resistant to the anorexigenic effects of leptin, greatly reducing the potency of leptin's inhibitory effects on the regulatory centers controlling appetite. In addition to its activity counter to ghrelin 
and NPY, leptin also blocks other appetite-stimulating signals. Leptin blocks anandamide (an appetite stimulant) and stimulates the release of an appetite-antagonist (a-MSH).

Given these mechanisms, administration of exogenous leptin has been tried as a treatment of obesity. In 1999, a multicenter, randomized, controlled trial showed promising results with weight loss occurring in both lean and obese subjects in response to escalating doses of leptin. ${ }^{53}$ However, subsequent studies using leptin for weight loss have failed to replicate this finding. ${ }^{54,55}$ It seems that leptin may be more effective as a marker for weight loss rather than an effector, and recent reports have confirmed that leptin levels decrease as weight is lost regardless of how this is achieved. ${ }^{56-58}$

Several studies have shown resolution of the leptin-resistance status after bariatric surgery procedures. ${ }^{30,46,56}$ Leptin levels decrease significantly in individuals who have had gastric bypass surgery and correlate with percent of weight loss.

\section{Enteroinsular Axis, Diabetes, and Bariatric Surgery}

One of the greatest benefits of bariatric surgery is the resolution in comorbid disease conditions such as type 2 diabetes mellitus. With more than 25 million Americans suffering from this disease and nearly $\$ 120$ billion spent annually on the treatment of diabetes, ${ }^{59}$ developing an effective treatment of diabetes is of utmost importance. Bariatric surgery has been shown to be more than just an effective treatment of diabetes; it is capable of achieving unrivaled therapeutic results. Supported by a growing body of evidence in the literature, the American Diabetes Association has endorsed bariatric surgery for the treatment of type 2 diabetes in patients with BMI greater than or equal to $35 \mathrm{~kg} / \mathrm{m}^{2}{ }^{60}$ Thus, understanding the mechanisms responsible for the high rate of diabetes resolution/remission after bariatric surgery is clinically relevant and may lead to new therapeutic targets.

As stated previously, bariatric surgery results in significant improvements in diabetes (and other comorbid conditions of obesity) before any significant weight loss has taken place, and this challenges the established notion that weight loss is the only mechanism for normalization of glucose metabolism. Studies have elucidated the effects of bariatric surgery on the enteroinsular axis; specifically on a family of peptides involved in the synthesis, secretion, and regulation of insulin: the incretins. ${ }^{61-64}$ Incretin levels have been shown to significantly change following bariatric surgery, and consequently there is much interest in developing novel techniques for using these hormones in the treatment of diabetes.

\section{Glucose-dependent Insulinotropic Peptide}

Glucose-dependent insulinotropic peptide (GIP), also known as gastric inhibitory polypeptide, is an incretin produced by the K-cells located within the mucosa of the duodenum and jejunum. GIP has several major roles in obesity and diabetes physiology: the regulation of pancreatic $\beta$-cells, control of glucose-dependent insulin and postprandial glucagon levels, and fatty acid metabolism. 65,66 It is thought that GIP is released by the proximal intestine in response to the presence of glucose within the lumen. The foregut hypothesis of bariatric surgery physiology is based mostly on this mechanism of GIP release. ${ }^{67,68}$ According to this theory, bariatric procedures that bypass the duodenum/ proximal jejunum (eg, RYGB) result in the complete exclusion of nutrients/glucose from the proximal intestines/foregut. This exclusion results in the loss of K-cell stimulation, a resultant reduction in GIP levels, and a reduction in $\beta$-cell stimulation/insulin release. It has been postulated that this mechanism is responsible for the early resolution of diabetes.

However, studies of GIP, its role in bariatric surgery, and the resolution of diabetes have not been conclusive. Although some have shown decreased levels in patients after RYGB, ${ }^{66,69}$ others have shown an increase or lack of change in GIP levels. ${ }^{41,61,66,70}$ These conflicting 
results are open for interpretation, and it is not well understood what role GIP has in bariatric surgery physiology.

\section{Glucagon-like Peptide-1}

Glucagon-like Peptide-1 (GLP-1) is another important incretin in the physiology of obesity. GLP-1 has many physiologic functions, including the stimulation of insulin secretion by the pancreas, an increase in the insulin sensitivity of pancreatic cells (a-cells and $\beta$-cells), inhibition of glucagon secretion, and reduction of hunger and food intake through activation of central regulatory centers of the brain. ${ }^{65,71}$ Released by L-cells in the distal gastrointestinal tract, namely the terminal ileum and colon, GLP-1 levels increase in response to the presence of nutrients in the lumen of the distal or hindgut intestines. Increasing the level of GLP-1 has been shown to induce appetite suppression in both obese and normal-weight humans, and it is also considered to be a component of the ileal brake mechanism. ${ }^{71,72}$ Again, this mechanism for appetite suppression and the termination of food intake is a negative-feedback circuit that is triggered by the presence of nutrients in the ileum and mediated by the anorexigenic properties of GLP-1 and PYY. ${ }^{46}$

In addition to its contributions to the ileal brake mechanism, it has been proposed that GLP-1 is a key factor leading to the rapid resolution/remission of diabetes mellitus after bariatric surgery. In contrast with the foregut hypothesis, the hindgut hypothesis proposes that RYGB allows faster arrival of nutrients into the hindgut, which then results in a quicker increase in GLP-1 levels. GLP-1 in turn alters metabolic physiology to limit further intake of nutrients, increase insulin production, and improve insulin sensitivity. ${ }^{72}$

\section{The Incretin Effect, Diabetes, and Bariatric Surgery}

Based on these results, there have been attempts to stimulate incretin release through intravenous glucose infusion. However, it has been shown that intravenous administration of glucose does not have the same intensity of effect on human metabolism and the enteroinsular axis as is seen after the same dose of orally ingested glucose. This effect has been called the incretin effect and gives additional relevance to the enteric production of incretins as an important mechanism by which glycemic control and remission of diabetes is achieved after bariatric surgery. ${ }^{73}$

In a randomized, prospective trial comparing the effects of RYGB and sleeve gastrectomy, both procedures resulted in improved insulin resistance (as measured by Homeostatic Model Assessment [HOMA]), diminished fasting insulin levels, and an increased postprandial GLP-1 response as early as 1 week following surgery, and before any significant weight loss. ${ }^{74}$ Another study confirmed these rapid effects of RYGB on insulin resistance and GLP-1, which resulted in $72 \%$ diabetes remission (defined as fasting glucose $<7 \mathrm{mmol} / \mathrm{L}$ and 2-hour glucose $<11.1 \mathrm{mmol} / \mathrm{L}$ after oral glucose tolerance test in subjects not on medications). ${ }^{75}$ However, despite similar weight loss results in the RYGB group, this same study showed that AGB and diet restriction did not result in any early improvements in insulin resistance or changes in postprandial GLP-1 levels, and diabetes remission was observed in only $17 \%$ after AGB. Although the RYGB effects on the enteroinsular axis are consistent with current understanding, the effects of sleeve gastrectomy are not well understood and require further study. In addition, diabetes resolution after AGB is likely more the result of caloric restriction and weight loss over time. In a recent randomized, controlled trial with close, long-term followup, AGB resulted in much higher rates of remission $(73 \%){ }^{76}$

In contrast, some investigators have tried to isolate and synthesize peptide signals that can replicate the effects of GIP and GLP-1, but there are unfavorable side effect profiles, 
variability in efficacy and bioavailability, and marginal outcome results. ${ }^{73,77}$ Although novel medical therapies hold promise, to date there exists no known substance or medication capable of modulating multiple mechanisms and achieving weight loss results and diabetes resolution with the speed and of the magnitude that are possible through bariatric surgery. Despite this, most of the lay public, and even some practitioners, still fail to recognize the benefits possible with metabolic and bariatric surgery.

Furthermore, current guidelines for the medical therapy for type 2 diabetes are based on a strategy of progressively increasing the number and types of diabetes medications, based on worsening glycemic control over time. This waiting-for-failure approach has been criticized because hyperglycemia itself may have immediate and sustained negative effects on the $\beta$ cell reserve, worsening a patient's prognosis for reversal of diabetes progression. It is thought that one of the factors associated with incomplete remission of diabetes after bariatric surgery is a long history of the disease. ${ }^{78}$ Likewise, other studies have shown that earlier glycemic control in diabetics can result in improved diabetes remission and preservation of $\beta$-cell function; ultimately resulting in a reduction of diabetes-related morbidity. ${ }^{77}$ The American Diabetes Association recently acknowledged the merits of bariatric surgery and recognized it as a viable treatment option in class II and III obese patients meeting the necessary prerequisites.

\section{SUMMARY}

Although the root cause of the current obesity epidemic has not been discovered, it warrants considerable attention and the appropriate use of all the treatment options available. As shown in Fig. 1, bariatric surgery is a proven and unrivaled treatment of obesity and the management of obesity-related diseases. Gastric bypass produces profound physiologic and metabolic changes in many organs as a result of surgical anatomic manipulation, as shown by the many studies available in the literature. However, understanding of the complex physiologic interactions that regulate energy homeostasis, appetite stimulation, and of the factors that provide the impetus for human obesity is still limited. Furthermore, the effects of bariatric surgery on obesity-related diseases such as diabetes are intriguing and present a tremendous potential for maximizing the treatment of millions of suffering Americans. Additional studies investigating the current hypotheses and theories of obesity and bariatric surgery should lead to new approaches for less invasive treatments.

This article only discusses half of the weight loss equation. As mentioned earlier, weight loss can only be achieved by balancing caloric intake and energy expenditure. However, novel ways of increasing human metabolism and developing an effective method for maximizing the amount of calories expended by the obese individual have not yet been discovered. Apart from increasing exercise and physical activities (which is difficult and, in some cases, impractical to initiate), there are no other means by which an increased metabolism can be achieved. Future research might capitalize on this untapped resource for developing novel treatments for obesity.

\section{Acknowledgments}

Dr Alfonso Torquati is supported by National Institute of Health grant K23 DK075907.

\section{REFERENCES}

1. Neel JV. Diabetes mellitus: a "thrifty" genotype rendered detrimental by "progress"? Am J Hum Genet. 1962; 14:353-62. [PubMed: 13937884]

2. Prentice AM, Hennig BJ, Fulford AJ. Evolutionary origins of the obesity epidemic: natural selection of thrifty genes or genetic drift following predation release? Int J Obes. 2008; 32:1607-10. 
3. Speakman JB. Thrifty genes for obesity, an attractive but flawed idea, and an alternative perspective: the 'drifty gene' hypothesis. Int J Obes. 2008; 32:1611-7.

4. Flegal KM, Carroll MD, Ogden CL, et al. Prevalence and trends in obesity among US adults, 1999-2008. JAMA. 2010; 303(3):235-41. [PubMed: 20071471]

5. Sjöström L, Narbro K, Sjöström CD, et al. Effects of bariatric surgery on mortality in Swedish obese subjects. N Engl J Med. 2007; 357(8):741-52. [PubMed: 17715408]

6. Buchwald H, Avidor Y, Braunwald E, et al. Bariatric surgery: a systematic review and metaanalysis. JAMA. 2004; 292(14):1724-37. [PubMed: 15479938]

7. DeMaria EJ, Pate V, Warthen M, et al. Baseline data from American Society for Metabolic and Bariatric Surgery-designated bariatric surgery centers of excellence using the bariatric outcomes longitudinal database. Surg Obes Relat Dis. 2010; 6(4):347-55. [PubMed: 20176512]

8. Flum DR, Belle SH, King WC, et al. Perioperative safety in the longitudinal assessment of bariatric surgery. N Engl J Med. 2009; 361(5):445-54. [PubMed: 19641201]

9. Frideman MN, Sancetta AJ, Magovern GJ. The amelioration of diabetes mellitus following subtotal gastrectomy. Surg Gynecol Obstet. 1955; 100(2):201-4. [PubMed: 13238177]

10. Pories WJ, Swanson MS, MacDonald KG, et al. Who would have thought it? An operation proves to be the most effective therapy for adult-onset diabetes mellitus. Ann Surg. 1995; 222(3):339-50. [PubMed: 7677463]

11. Power ML, Schulkin J. Anticipatory physiological regulation in feeding biology: cephalic phase responses. Appetite. 2008; 50(2):194-206. [PubMed: 18045735]

12. Ochner CN, Kwok Y, Coceicao E, et al. Selective reduction in neural responses to high calorie foods following gastric bypass surgery. Ann Surg. 2011; 253(3):502-7. [PubMed: 21169809]

13. Sakata I, Sakai T. Ghrelin cells in the gastrointestinal tract. Int J Pept. 2010 DOI: 10.1155/2010/945056.

14. Cummings DE, Purnell JQ, Frayo RS, et al. A preprandial rise in plasma ghrelin levels suggests a role in meal initiation in humans. Diabetes. 2001; 50(8):1714-9. [PubMed: 11473029]

15. Diniz Mde F, Passos VM Azeredo, Diniz MT. Bariatric surgery and the gut-brain communicationthe state of the art three years later. Nutrition. 2010; 10:925-31. [PubMed: 20392599]

16. Cummings DE, Overduin J. Gastrointestinal regulation of food intake. J Clin Investig. 2007; 117:13-23. [PubMed: 17200702]

17. Hansen TK, Dall R, Hosoda H, et al. Weight loss increases circulating levels of ghrelin in human obesity. Clin Endocrinol. 2002; 56:203-6.

18. Wren AM, Bloom SR. Gut hormones and appetite control. Gastroenterology. 2007; 132:2116-57. [PubMed: 17498507]

19. Marzullo P, Verti B, Savia G, et al. The relationship between active ghrelin levels and human obesity involves alterations in resting energy expenditure. J Clin Endocrinol Metab. 2004; 89(2): 936-9. [PubMed: 14764817]

20. Shiiya T, Nakazato M, Mizuta M, et al. Plasma ghrelin levels in lean and obese humans and the effect of glucose on ghrelin secretion. J Clin Endocrinol Metab. 2002; 87(1):240-4. [PubMed: 11788653]

21. English PJ, Ghatei MA, Malik IA, et al. Food fails to suppress ghrelin levels in obese humans. J Clin Endocrinol Metab. 2002; 87(6):2984. [PubMed: 12050284]

22. Tritos NA, Mun E, Bertkau A, et al. Serum ghrelin levels in response to glucose load in obese subjects post-gastric bypass surgery. Obes Res. 2003; 11(8):919-24. [PubMed: 12917494]

23. Cummings DE, Weigle DS, Frayo RS, et al. Plasma ghrelin levels after diet-induced weight loss or gastric bypass surgery. N Engl J Med. 2002; 346(21):1623-30. [PubMed: 12023994]

24. Oliván B, Teixeira J, Bose M, et al. Effect of weight loss by diet or gastric bypass surgery on peptide YY3-36 levels. Ann Surg. 2009; 249(6):948-53. [PubMed: 19474685]

25. Kelishadi R, Hashemipour M, Mohammadifard N, et al. Short- and long-term relationships of serum ghrelin with changes in body composition and the metabolic syndrome in prepubescent obese children following two different weight loss programmes. Clin Endocrinol. 2008; 69(5): 721-9. 
26. Schur EA, Cummings DE, Callahan HS, et al. Association of cognitive restraint with ghrelin, leptin, and insulin levels in subjects who are not weight-reduced. Physiol Behav. 2008; 93(4-5): 706-12. [PubMed: 18164043]

27. Morínigo R, Casamitjana R, Moizé V, et al. Short-term effects of gastric bypass surgery on circulating ghrelin levels. Obes Res. 2004; 12:1108-16. [PubMed: 15292475]

28. Frühbeck G, Rotellar F, Hernández-Lizoain JL, et al. Fasting plasma ghrelin concentrations 6 months after gastric bypass are not determined by weight loss or changes in insulinemia. Obes Surg. 2004; 14:1208-15. [PubMed: 15527636]

29. Shak JR, Roper J, Perez-Perez GI, et al. The effect of laparoscopic gastric banding surgery on plasma levels of appetite-control, insulinotropic, and digestive hormones. Obes Surg. 2008; 18:1089-96. [PubMed: 18408980]

30. Faraj M, Havel PJ, Phélis S, et al. Plasma acylation-stimulating protein, adiponectin, leptin, and ghrelin before and after weight loss induced by gastric bypass surgery in morbidly obese subjects. J Clin Endocrinol Metab. 2003; 88:1594-602. [PubMed: 12679444]

31. Holdstock C, Engström BE, Ohrvall M, et al. Ghrelin and adipose tissue regulatory peptides: effect of gastric bypass surgery in obese humans. J Clin Endocrinol Metab. 2003; 88:3177-83. [PubMed: 12843162]

32. Soares JB, Leite-Moreira AF. Ghrelin, des-acyl ghrelin and obestatin: three pieces of the same puzzle. Peptides. 2008; 29(7):1255-70. [PubMed: 18396350]

33. Dixon AF, Dixon JB, O’Brien PE. Laparoscopic adjustable gastric banding induces prolonged satiety: a randomized blind crossover study. J Clin Endocrinol Metab. 2005; 90(2):813-9. [PubMed: 15585553]

34. Wang Y, Liu J. Plasma ghrelin modulation in gastric band operation and sleeve gastrectomy. Obes Surg. 2009; 19(3):357-62. [PubMed: 18841429]

35. le Roux CW, Neary NM, Halsey TJ, et al. Ghrelin does not stimulate food intake in patients with surgical procedures involving vagotomy. J Clin Endocrinol Metab. 2005; 90(8):4521-4. [PubMed: 15914532]

36. Nogueiras, R.; Wilson, H.; Perez-Tilve, D., et al. The role of the gastrointestinal hormones ghrelin, peptide YY, and glucagon-like peptide-1 in the regulation of energy balance. In: Donohoue, PA., editor. Energy metabolism and obesity: research and clinical applications. Humana Press; Totowa (NJ): 2008. p. 107-24.

37. Hanson ES, Dallman MF, Neuropeptide Y. NPY) may integrate responses of hypothalamic feeding systems and the hypothalamo-pituitary-adrenal axis. J Neuroendocrinol. 1995; 7(4):273-9. [PubMed: 7647769]

38. Dryden S, Pickavance L, Frankish HM, et al. Increased neuropeptide Y secretion in the hypothalamic paraventricular nucleus of obese (fa/fa) Zucker rats. Brain Res. 1995; 690(2):185-8. [PubMed: 8535835]

39. Kuo LE, Kitlinska JB, Tilan JU, et al. Neuropeptide Y acts directly in the periphery on fat tissue and mediates stress-induced obesity and metabolic syndrome. Nat Med. 2007; 13(7):803-11. [PubMed: 17603492]

40. Erondu N, Gantz I, Musser B, et al. Neuropeptide Y5 receptor antagonism does not induce clinically meaningful weight loss in overweight and obese adults. Cell Metab. 2006; 4(4):275-82. [PubMed: 17011500]

41. Whitson BA, Leslie DB, Kellogg TA, et al. Entero-endocrine changes after gastric bypass in diabetic and nondiabetic patients: a preliminary study. J Surg Res. 2007; 141(1):31-9. [PubMed: 17574036]

42. Ballantyne GH. Peptide YY(1-36) and peptide YY(3-36): part I. Distribution, release and actions. Obes Surg. 2006; 16(5):651-8. [PubMed: 16687037]

43. Pironi L, Stanghellini V, Miglioli M, et al. Fat-induced ileal brake in humans: a dose-dependent phenomenon correlated to the plasma levels of peptide YY. Gastroenterology. 1993; 105(3):7339. [PubMed: 8359644]

44. Jayasena CN, Bloom SR. Role of gut hormones in obesity. Endocrinol Metab Clin North Am. 2008; 37(3):769-88. [PubMed: 18775363] 
45. le Roux CW, Bloom SR. Peptide YY, appetite and food intake. Proc Nutr Soc. 2005; 64(2):213-6. [PubMed: 15960866]

46. Beckman LM, Beckman TR, Earthman CP. Changes in gastrointestinal hormones and leptin after Roux-en-Y gastric bypass procedure: a review. J Am Diet Assoc. 2010; 110(4):571-84. [PubMed: 20338283]

47. Sloth B, Holst JJ, Flint A, et al. Effects of PYY1-36 and PYY3-36 on appetite, energy intake, energy expenditure, glucose and fat metabolism in obese and lean subjects. Am J Physiol Endocrinol Metab. 2007; 292(4):E1062-8. [PubMed: 17148749]

48. Batterham RL, Cohen MA, Ellis SM, et al. Inhibition of food intake in obese subjects by peptide YY3-36. N Engl J Med. 2003; 349(10):941-8. [PubMed: 12954742]

49. le Roux CW, Welbourn R, Werling M, et al. Gut hormones as mediators of appetite and weight loss after Roux-en-Y gastric bypass. Ann Surg. 2007; 246(5):780-5. [PubMed: 17968169]

50. Korner J, Inabnet W, Febres G, et al. Prospective study of gut hormone and metabolic changes after adjustable gastric banding and Roux-en-Y gastric bypass. Int J Obes. 2009; 33(7):786-95.

51. Karamanakos SN, Vagenas K, Kalfarentzos F, et al. Weight loss, appetite suppression, and changes in fasting and postprandial ghrelin and peptide-YY levels after Roux-en-Y gastric bypass and sleeve gastrectomy: a prospective, double blind study. Ann Surg. 2008; 247(3):401-17. [PubMed: 18376181]

52. Sikaris KA. The clinical biochemistry of obesity. Clin Biochem. 2004; 25(3):165-81.

53. Heymsfield SB, Greenberg AS, Fujioka K, et al. Recombinant leptin for weight loss in obese and lean adults: a randomized, controlled, dose-escalation trial. JAMA. 1999; 282(16):1568-75. [PubMed: 10546697]

54. Fogteloo AJ, Pijl H, Frölich M, et al. Effects of recombinant human leptin treatment as an adjunct of moderate energy restriction on body weight, resting energy expenditure and energy intake in obese humans. Diabetes Nutr Metab. 2003; 16(2):109-14. [PubMed: 12846450]

55. Zelissen PM, Stenlof K, Lean ME, et al. Effect of three treatment schedules of recombinant methionyl human leptin on body weight in obese adults: a randomized, placebo-controlled trial. Diabetes Obes Metab. 2005; 7(6):755-61. [PubMed: 16219020]

56. Ram E, Vishne T, Maayan R, et al. The relationship between BMI, plasma leptin, insulin and proinsulin before and after laparoscopic adjustable gastric banding. Obes Surg. 2005; 15(10): 1456-62. [PubMed: 16354527]

57. Kotidis EV, Koliakos GG, Baltzopoulos VG, et al. Serum ghrelin, leptin and adiponectin levels before and after weight loss: comparison of three methods of treatment-a prospective study. Obes Surg. 2006; 16(11):1425-32. [PubMed: 17132406]

58. Pardina E, Ferrer R, Baena-Fustegueras JA, et al. The relationships between IGF-1 and CRP, NO, leptin, and adiponectin during weight loss in the morbidly obese. Obes Surg. 2010; 20(5):623-32. [PubMed: 20195789]

59. Centers for Disease Control and Prevention. National diabetes fact sheet: national estimates and general information on diabetes and prediabetes in the United States, 2011. US Department of Health and Human Services, Centers for Disease Control and Prevention; Atlanta (GA): 2011.

60. American Diabetes Association. Standards of medical care in diabetes - 2011. Diabetes Care. 2011; 34(Suppl 1):S11-61. [PubMed: 21193625]

61. Bose M, Teixeira J, Olivan B, et al. Weight loss and incretin responsiveness improve glucose control independently after gastric bypass surgery. J Diabetes. 2010; 2(1):47-55. [PubMed: 20676394]

62. Laferrère B. Effect of gastric bypass surgery on the incretins. Diabetes Metab. 2009; 35(6 Pt 2): 513-7. [PubMed: 20152736]

63. Kashyap SR, Daud S, Kelly KR, et al. Acute effects of gastric bypass versus gastric restrictive surgery on beta-cell function and insulinotropic hormones in severely obese patients with type 2 diabetes. Int J Obes. 2010; 34(3):462-71.

64. Isbell JM, Tamboli RA, Hansen EN, et al. The importance of caloric restriction in the early improvements in insulin sensitivity after Roux-en-Y gastric bypass surgery. Diabetes Care. 2010; 33(7):1438-42. [PubMed: 20368410] 
65. Efendic S, Portwood N. Overview of incretin hormones. Horm Metab Res. 2004; 36(11-12):7426. [PubMed: 15655702]

66. Rao RS, Kini S. GIP and bariatric surgery. Obes Surg. 2011; 21(2):244-52. [PubMed: 21082290]

67. Theodorakis MJ, Carlson O, Muller DC, et al. Elevated plasma glucose-dependent insulinotropic polypeptide associates with hyperinsulinemia in impaired glucose tolerance. Diabetes Care. 2004; 27(7):1692-8. [PubMed: 15220248]

68. Hickey MS, Pories WJ, MacDonald KG Jr, et al. A new paradigm for type 2 diabetes mellitus: could it be a disease of the foregut? Ann Surg. 1998; 227:637-43. [PubMed: 9605655]

69. Rubino F, Forgione A, Cummings DE, et al. The mechanism of diabetes control after gastrointestinal bypass surgery reveals a role of the proximal small intestine in the pathophysiology of type 2 diabetes. Ann Surg. 2006; 244:741-9. [PubMed: 17060767]

70. Laferrère B, Heshka S, Wang K, et al. Incretin levels and effect are markedly enhanced 1 month after Roux-en-Y gastric bypass surgery in obese patients with type 2 diabetes. Diabetes Care. 2007; 30(7):1709-16. [PubMed: 17416796]

71. Doyle ME, Egan JM. Glucagon-like peptide-1. Recent Prog Horm Res. 2001; 56:377-99. [PubMed: 11237222]

72. Thomas S, Schauer P. Bariatric surgery and the gut hormone response. Nutr Clin Pract. 2010; 25(2):175-82. [PubMed: 20413698]

73. Barber TM, Begbie H, Levy J. The incretin pathway as a new therapeutic target for obesity. Maturitas. 2010; 67(3):197-202. [PubMed: 20655673]

74. Peterli R, Wölnerhanssen B, Peters T, et al. Improvement in glucose metabolism after bariatric surgery: comparison of laparoscopic Roux-en-Y gastric bypass and laparoscopic sleeve gastrectomy: a prospective randomized trial. Ann Surg. 2009; 250(2):234-41. [PubMed: 19638921]

75. Pournaras DJ, Osborne A, Hawkins SC, et al. Remission of type 2 diabetes after gastric bypass and banding: mechanisms and 2 year outcomes. Ann Surg. 2010; 252(6):966-71. [PubMed: 21107106]

76. Dixon JB, O'Brien PE, Playfair J, et al. Adjustable gastric banding and conventional therapy for type 2 diabetes: a randomized controlled trial. JAMA. 2008; 299(3):316-23. [PubMed: 18212316]

77. Piya MK, Tahrani AA, Barnett AH. Emerging treatment options for type 2 diabetes. Br J Clin Pharmacol. 2010 [Epub ahead of print]. DOI: 10.1111/j.1365-2125.2010.03711.x.

78. Deitel M. Update: why diabetes does not resolve in some patients. Obes Surg. 2011; 21(6):794-6. [PubMed: 21108020] 


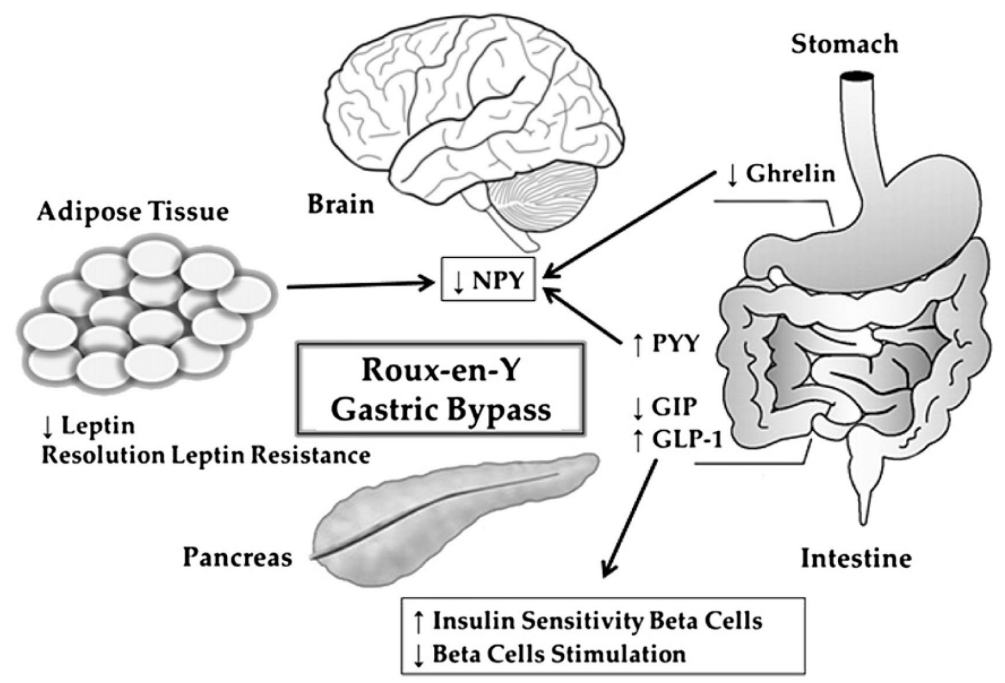

Fig. 1.

The effect of gastric bypass surgery is mediated by changes in the brain, stomach, intestine, pancreas, and adipose tissue. 